\title{
AIR AND WET BULB TEMPERATURE LAPSE RATES AND THEIR IMPACT ON SNOWMAKING IN A PYRENEAN SKI RESORT
}

López-Moreno, J.I. ${ }^{1}$, Navarro-Serrano, F. ${ }^{1}$, Azorín-Molina, C. ${ }^{2}$ Sánchez-Navarrete, P. ${ }^{1}$, Alonso-González, E. ${ }^{1}$, Rico, I. ${ }^{1,3}$, Morán-Tejeda, E. ${ }^{7}$, Buisan, S. ${ }^{4}$, Revuelto, J. ${ }^{5}$, Pons, M. $^{6}$, Vicente-Serrano, S.M. ${ }^{1}$

1- Instituto Pirenaico de Ecología, CSIC. Avda. Montañana 1005. Zaragoza 50.059. Spain

2- Regional Climate Group, Department of Earth Sciences, University of Gothenburg, Sweden

3- Universidad del País Vasco. Departamento de Geografía, Prehistoria y Arqueología. Vitoria Gasteiz, Spain

4- AEMET, Spanish Meteorological Service. Zaragoza, Spain.

5- Météo-France - CNRS, CNRM UMR3589, Centre d'Etudes de la Neige, Grenoble, France

6- Snow and Mountain Research Center of Andorra. Andorran Research Institute, Sant Julià, Andorra

7- University of the Balearic Islands. Department of Geography. Palma, Spain

Corresponding author: Juan Ignacio López Moreno:

nlopez@ipe.csic.es

Instituto Pirenaico de Ecología, CSIC.

Campus de Aula Dei, Avda Montañana 1005

Zaragoza 50.059.

España

Tlf: 976369393 ext. $990036 /$ Fax: 976369396 


\section{Air and wet bulb temperature lapse rates and their impact on snowmaking in a Pyrenean ski resort}

López-Moreno, J.I. ${ }^{1}$, Navarro-Serrano, F. ${ }^{1}$, Azorín-Molina, C. ${ }^{2}$ Sánchez-Navarrete, P. ${ }^{1}$, Alonso-González, E. ${ }^{1}$, Rico, I. ${ }^{1,3}$, Morán-Tejeda, E. ${ }^{7}$, Buisan, S. ${ }^{4}$, Revuelto, J. ${ }^{5}$, Pons, M. $^{6}$, Vicente-Serrano, S.M. ${ }^{1}$

2- Instituto Pirenaico de Ecología, CSIC. Avda. Montañana 1005. Zaragoza 50.059. Spain

2- Regional Climate Group, Department of Earth Sciences, University of Gothenburg, Sweden

3- Universidad del País Vasco. Departamento de Geografía, Prehistoria y Arqueología. Vitoria Gasteiz, Spain

4- AEMET, Spanish Meteorological Service. Zaragoza, Spain.

5- Météo-France - CNRS, CNRM UMR3589, Centre d'Etudes de la Neige, Grenoble, France

6- Snow and Mountain Research Center of Andorra. Andorran Research Institute, Sant Julià, Andorra

7- University of the Balearic Islands. Department of Geography. Palma, Spain

Abstract. A set of 17 air temperature and relative humidity sensors were used to analyze the temporal variability of surface air temperature (Tair), wet bulb temperature (Twb), and daily snow making hours (SM, number of hours per day with $\mathrm{Twb}<-2^{\circ} \mathrm{C}$ ) lapse rates and the occurrence of thermal inversions at the Formigal ski resort (Spanish Pyrenees) from December to March during three consecutive ski seasons (2012-2013, 2013-2014, and 2014-2015). The Tair and Twb lapse rates showed strong hourly and daily variability, with both exhibiting almost identical temporal fluctuations.

The Twb exhibited average lapse rates that were slightly steeper $\left(-5.2^{\circ} \mathrm{C} / \mathrm{km}\right)$ than those observed for Tair $\left(-4.9^{\circ} \mathrm{C} / \mathrm{km}\right)$. The less steep lapse rates and most thermal inversions were observed in December. Days having less (more) steep Tair and Twb lapse rates were observed under low (high) wind speeds and high (low) relative humidity and air pressure. The temporal dynamics of the SM lapse rates was more complex, as this involved consideration of the average Tair in the ski resort, in addition to the driving factors of the spatio-temporal variability of Twb. Thus, on a number of cold (warm) days snow making was feasible at all elevations at the ski resort, independently of the slopes of the lapse rates. The SM exhibited an average daily lapse rate of $8.2 \mathrm{~h} / \mathrm{km}$, with a progressive trend of increase from December to March. 
Weather types over the Iberian Peninsula tightly control the driving factors of the Tair, Twb, and SM lapse rates (wind speed, relative humidity, and Tair), so the slopes of the lapse rates and the frequency of inversions in relation to elevation for the three variables are very dependent on the occurrence of specific weather types. The less steep lapse rates occurred associated with advections from the southeast, although low lapse rates also occurred during advections from the east and south, and under anticyclonic conditions. The steepest Tair and Twb lapse rates were observed during north and northwest advections, whilst the steepest rates for SM were observed during days of cyclonic circulation and advections from the northeast.

Keywords. snow making, air temperature, wet bulb temperature, lapse rates, Pyrenees

\section{Introduction}

In recent decades ski tourism has become one of the most important sources of income for many mountain regions worldwide (Gilaberte et al., 2014). Despite their obvious environmental impacts, ski developments provide for economic and income diversification, and are associated with improvements to services and infrastructure (Lindberg et al., 2001; Lasanta et al., 2007). However, the economic viability of skibased tourism relies on the presence of adequate snow depths during the ski season (Steiger and Mayer, 2008; Scott et al., 2012; Pons et al., 2015). This is a major challenge for winter sport destinations (Rixen et al., 2011), especially those located at mid-latitudes or in low elevation areas, where the snowpack is characterized by strong interannual fluctuations, and global warming is acting to diminish the snowpack (López-Moreno et al., 2009).

In low elevation ski areas, snow making represents a key technology to buffer the impact of interannual variability of snow conditions, and is increasingly considered to be the most reliable adaptation measure for alpine ski resorts facing the consequences of climate change (Uhlmann et al., 2009; Spandre et al., 2017). However, for successful and efficient production of machine-made snow, particular air temperature and humidity conditions need to be met, generally defined by a wet bulb temperature (Twb) threshold. This threshold is not always met, especially at lower elevation sites where the natural snowpack is less abundant because (López-Moreno et al., 2017). For this reason the use of snowmaking is questioned, and discouraged in those areas were the potential for regular snow production is uncertain under short-term climate projection scenarios that indicate declining conditions for skiing and snow production in coming decades 
(Gilaberte et al., 2017). Thus, to assess the potential for snowmaking to overcome the large spatial and temporal variability of natural snowpacks it is imperative to understand the spatial and temporal dynamics of Twb within ski resorts. No such studies have yet been reported.

The Twb is the temperature of a particular volume of air cooled to saturation $(100 \%$ relative humidity) by the evaporation of water into it, and is always less than or equal to dry Tair. The more moisture in a parcel of air the less moisture it can absorb, and the colder it must become to form snow crystals from the fine droplets of water. Depending on the snowmaking technology, Twb values colder than $-1^{\circ}$ to $-4^{\circ} \mathrm{C}$ are commonly used as thresholds for snow production. At the local scale (i.e. within a ski resort), the spatial variability of relative humidity $(\mathrm{RH})$ is mostly determined by Tair because the specific humidity (the water content of air) tends to be highly spatially homogeneous (Brutsaert, 1998). At local scales most of the variability in Tair is because of vertical changes described by the so-called environmental lapse rate (ELR), which is assumed to be $-6.5^{\circ} \mathrm{C} / \mathrm{km}$ under neutral conditions in free atmosphere (Frederick, 2008); this value is commonly used to spatially interpolate and extrapolate air temperature (LópezMoreno et al., 2017). However, many studies have indicated that numerous factors make air temperature gradients very site-specific, including topography (slope, aspect, sky view factor), the presence of snow and ice, and vegetation and soil types (Nuñez and Calhoun, 1986; Roland, 2003; Marshall, 2007; Blandford et al., 2008; Pepin and Lundquist, 2008, Pages and Miro, 2010; Kattel et al., 2013). In addition, Tair lapse rates are highly dependent on surface processes (Minder et al., 2010) including air moisture, wind speed, atmospheric pressure, and solar radiation, and this explains the very strong temporal variability in the slope of ELR at sub-daily to seasonal and interannual scales (Thayyen et al., 2005, Tang and Fang, 2006; Gardner et al., 2009, Heynen et al., 2016). The various meteorological conditions affecting ELRs are generally associated with the passage of air masses having differing characteristics (Kirchner et al., 2013), providing the potential to establish the relationships of various weather types and synoptic conditions to the slopes of the ELRs (Pepin 2001; Blanford et al., 2008; Holden and Rose, 2011).

Thus, knowledge of the spatio-temporal evolution of Tair and Twb temperatures is essential for mountain areas where artificial snow production is important in management of ski resorts. In this study, based on the ski resort of Formigal (Spanish Pyrenees), we used hourly data from 17 sensors measuring temperature and relative 
humidity over three consecutive ski seasons (2013-14, 2014-15, and 2015-16) to assess the temporal variability of the Tair and Twb lapse rates, and their impacts on the production of artificial snow. The effects of meteorological factors and the weather types on the slope of the lapse rates were also analyzed.

\section{Study area}

This study was carried out at the Formigal Ski Resort (Central Pyrenees; $42.5^{\circ} \mathrm{N}$ $0.25^{\circ} \mathrm{W}$; Fig. 1), which is the largest ski area in the Spanish Pyrenees, comprising 137 $\mathrm{km}$ of ski runs. Elevations at Formigal range from 1550 to $2300 \mathrm{~m}$ a.s.l., and the lifts have a maximum capacity of 35,920 skiers per hour. The ski season generally starts in early December and finishes in early April.

Data from the automatic weather stations at Izas (2056 $\mathrm{m}$ a.s.1.), which is located in the vicinity of this ski area, indicates a mean annual Tair of $3^{\circ} \mathrm{C}$ and an average of 130 days each year when the daily mean Tair is $<0^{\circ} \mathrm{C}$ (Revuelto et al., 2017). The mean annual precipitation is approximately $2000 \mathrm{~mm}$, of which more than 50\% falls as snow (LópezMoreno et al., 2013). Although the mean winter Tair is $<0^{\circ} \mathrm{C}$, the area is subject to temperate or rainy spells during winter, which trigger melting events and major metamorphosis of the snowpack throughout the snow season (Fassnacht et al., 2010). The wind direction is predominantly from northwest and southeast (Revuelto et al., 2014, 2017; Navarro-Serrano and López-Moreno, 2017).

\section{Data and methods}

One measurement per hour of Tair and RH were obtained from 17 Tinytag TGP-4500 data loggers (www.geminidataloggers.com/data-loggers/tinytag-plus-2/tgp-4500) evenly placed in an area of $12 \mathrm{~km}^{2}$ within the Formigal ski resort (Fig. 1); these provided data for 331 days during the three seasons of the study. The manufacturer's stated accuracy for the sensors is $\pm 0.01{ }^{\circ} \mathrm{C}$ for Tair and $\pm 0.3 \%$ for $\mathrm{RH}$. The data loggers were hung from the eaves of the roofs of chair lift sheds, at approximately $2.5 \mathrm{~m}$ height above the bare ground, and were protected by radiation shields (DataMate ${ }^{\mathrm{TM}}$ ). The lowest sensor was at $1554 \mathrm{~m}$ a.s.l. and the highest was at $2305 \mathrm{~m}$ a.s.l., at the top of the ski area. At least one sensor was placed in each 100-m elevation band in the two main valleys of the ski area. There is also an automatic weather station at $2056 \mathrm{~m}$ a.s.l. in the study area; this records temperature (Tair), wind speed (WS), RH, and air pressure (Pat) 
every $10 \mathrm{~min}$. The data for Tair and RH from this station provided an extra sensor for the study (i.e. total $=18$ ). The WS, RH, and Pat parameters were used as explanatory variables for temporal fluctuations of the lapse rates for Tair, Twb, and the snow making hours $\left(\mathrm{SM}, \mathrm{Twb}<-2^{\circ} \mathrm{C}\right)$.

Figure 1. Study area. Location of the temperature (Temp.) and relative humidity (RH) sensors, and the meteorological station. Contour lines are drawn for every 200 meters of elevation.

The Twb was calculated from Tair and RH using the equation of Stull (2011), which presented a mean absolute error $<0.3^{\circ} \mathrm{C}$ :

$\mathrm{Twb}=$ Tair $\times \tan \left[0.151977(\mathrm{RH}+8.313659)^{1 / 2}\right]+\operatorname{atan}(\mathrm{Tair}+\mathrm{RH})-\operatorname{atan}(\mathrm{RH}-$ $1.676331)+0.00391838(\mathrm{RH})^{3 / 2} \operatorname{atan}(0.023101 \mathrm{RH} \%)-4.686035$

From the hourly Twb series, it was set the daily number of hours of snowmaking (SM hours) summing all hours per day with $\mathrm{Twb}<-2^{\circ} \mathrm{C}$ at each sensor. This threshold was based on the technical specifications of the 440 snow guns (Technoalpin TL6 and M18) installed in the ski area. The slopes of the linear regressions of Tair, Twb, and SM hours 
as a function of elevation were used as measures of the lapse rates, and the Pearson's $r$ coefficient was used to assess the strength of the correlations. A threshold of $p<0.05$ was used to assess whether the relationships were statistically significant. Significant correlations for data from the 17 data loggers corresponded to $\mathrm{r}$ values less than and greater than -0.41 and +0.41 , respectively.

The relationships of the Twb and SM daily lapse rates to average daily WS, RH, Pat, and Tair were assessed. The interactions amongst variables were explored using regression tree classification models (Breiman et al., 1984); these are non-parametric methods based on recursive splitting of the information from the predictor variables to minimize the sum of the squared residuals obtained in each group. The complexity of the final tree is generally based on the tree size that minimizes model deviance from cross-validation measures, and maximizes the coefficient of determination (Molotch et al., 2005). Similarly, the tree size was fitted based on a $1 \%$ threshold for the relationship of reduced variance to complexity for a sequence in the pruned tree, and assignment of a minimum node size (at least 20 observations per node).

To explore the dependence of the Tair, Twb, and SM lapse rates on the passage of air masses having different characteristics and trajectories, a classification of weather types over the Iberian Peninsula was conducted. Daily weather types for the Iberian Peninsula were classified as described by Jenkinson and Collison (1977). The method is based on an index obtained from the direction and vorticity of geostrophic wind, calculated from daily sea level pressure data at 16 points that form a grid of $5^{\circ}$ latitude encompassing the Iberian Peninsula. This method has been fully explained and discussed by Jones et al. (1993) and Trigo and DaCamara (2000), and successfully applied to the Iberian Peninsula (Goodess and Palutikof, 1998; Spellman, 2000; Trigo and Dacamara, 2000; López-Moreno and Vicente-Serrano, 2007). This classification generates 26 circulation weather types (CWTs): anticyclonic (A), cyclonic (C), 8 directional and 16 hybrid CWTs. The number of types was reduced by assigning the 16 hybrid CWTs according to their directional flow; for example, ANE (anticyclonic-northeast) was classified as NE (northeast). This enabled interpretation of the results to be simplified to 2 pure (A, C) and 8 directional (N, NE, E, SE, S, SW, W, NW) CWTs. Following a modified version of the procedure of Rasilla et al. (2002), unclassified (U) days were reclassified using two rules based on the sea level pressure at point 8 on the grid (p8; located approximately over Lisbon, on the west Iberian Peninsula), plus a third rule introduced for this analysis: 
- $\quad$ p8 < $1020 \mathrm{mb}$ : Cyclonic (C)

- $1020<\mathrm{p} 8<1030 \mathrm{mb}$ : Anticyclonic (A)

- $\quad$ p8 > $1030 \mathrm{mb}$ : Severe Anticyclonic $(\mathrm{A}+)$

The selection of $\mathrm{p} 8$ was based on it being closest to a center in the Iberian Peninsula grid. We added the Severe Anticyclonic (A+) type because we detected a much stronger relationship between the near surface temperature lapse rate (NSLR) and A+ days compared with generic anticyclonic situations.

\section{Results}

Figure 2 shows the daily fluctuations in the Tair and Twb lapse rates during the three ski seasons in the study (Fig. 2A), the frequency distribution of the lapse rates, and the coefficient of correlation between elevation and Tair, Twb, and daily SM hours during each ski season and in each month for the period December-March (Figs 2B-D). The plots show that there were very large daily fluctuations in the lapse rates and very similar values for Tair and Twb, which averaged -4.9 and $-5.2^{\circ} \mathrm{C} \mathrm{km}^{-1}$ (respectively) over the entire study period. During December the average lapse rates were the least steep $\left(-2.9\right.$ and $-3.1^{\circ} \mathrm{C} / \mathrm{km}$, respectively) and the coefficients of correlation were lower than during the other periods of the snow season. January had the most variable lapse rates and coefficients of variation, but the average and median values (approximately -5 and $-6^{\circ} \mathrm{C} \mathrm{km}^{-1}$, respectively) were similar to the values for February and March. The relationship between elevation and snowmaking hours is on average $8.2 \mathrm{~h} \mathrm{~km}^{-1}$, and the correlations exhibit much lower values compared to Tair and Twb. Both the lapse rates and the correlation coefficients tended to increase during each ski season. 

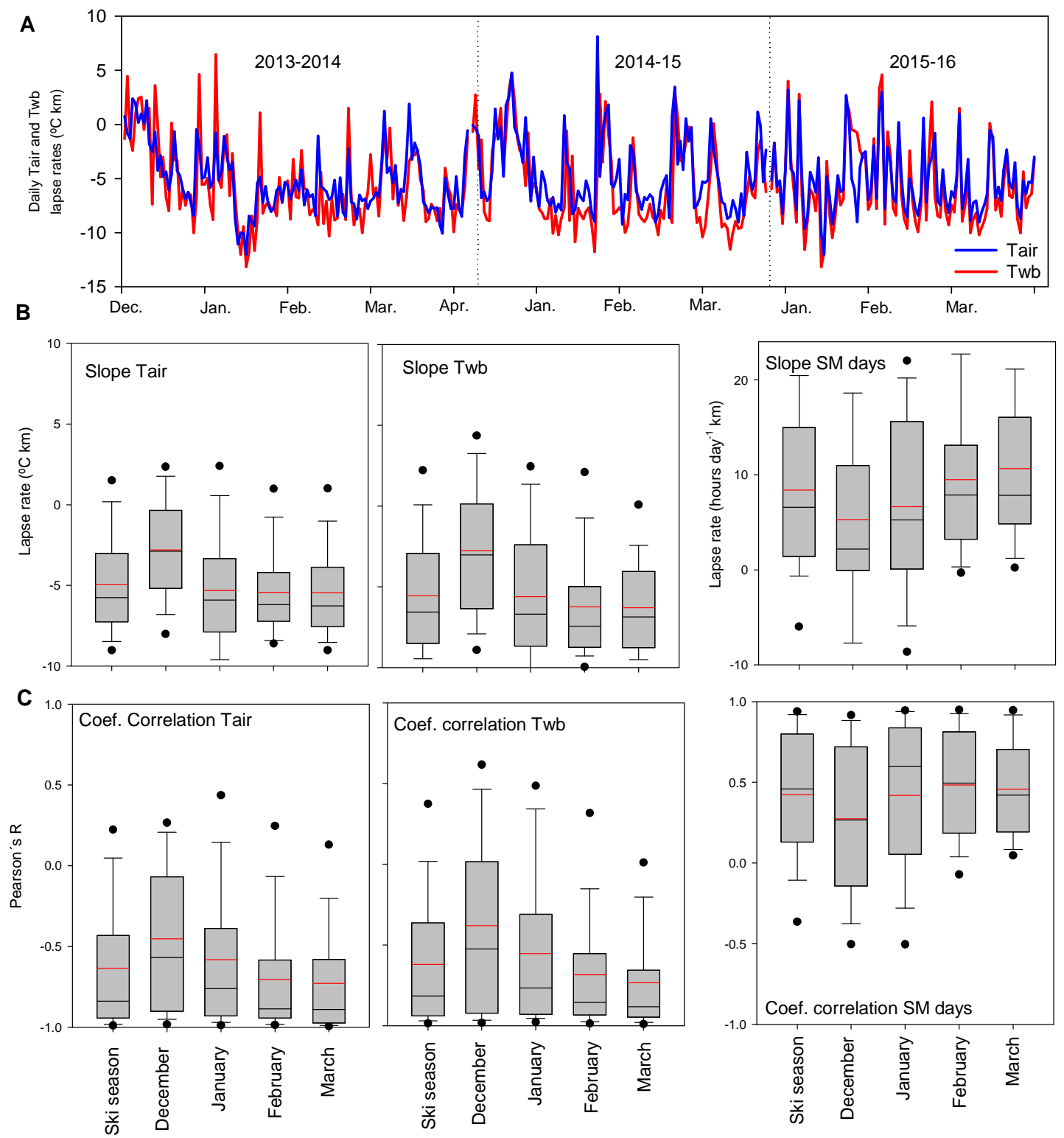

Figure 2. Average daily Tair and Twb lapse rates for the three ski seasons in the study (A); and the frequency distribution of lapse rates (B) and the coefficients of correlation (C) between elevation and Tair, Twb and SM hours Tair, Twb, and SM hours (C). Horizontal lines indicate the interannual mean (red) and median (black) values, the boxes indicate the 25th and 75th percentiles, the bars indicate the 10th and 90th percentile, and the dots indicate the 5th and 95th percentiles.

Figure 3 shows the daily number of hours having a Twb value below $-2^{\circ} \mathrm{C}$ (bottom plot), calculated from the daily Twb lapse rates at three different elevations in the ski resort (1550, 1900, and $2250 \mathrm{~m}$ a.s.1.), and illustrates the effect of average Tair on the lapse rates for SM. This figure also shows that during cold periods there are not lapse rates because there are conditions for SM throughout the day at the three elevations. However, under warmer Tair conditions the lapse rates in Twb caused marked 
differences, with several days having 24 hours of SM conditions at $2250 \mathrm{~m}$ a.s.l. but only 10-15 hours at the lowest elevation. Thus, during warmer days when it was only possible to produce snow for a few hours at the highest elevation, the conditions for snowmaking at lower elevations did not exist. For only a few days during the three snow seasons was snowmaking not possible at any time of the day at $2250 \mathrm{~m}$ a.s.l.

Figure 3 also shows that there were a number of days when there were more hours of potential SM at lower elevations than at higher elevations, as a consequence of thermal inversions. On these days the low Twb temperatures enabled SM at the three elevations. However, on other days the Twb was more than $2^{\circ} \mathrm{C}$ lower in the valleys bottoms compared with the upper slopes. This explains the mismatch between the number of inversion days in Twb and SM shown in Figure 3.

Table 1 shows the total and monthly frequencies of days when cooling of the snowpack was not significantly $(\mathrm{p}<0.05)$ correlated with elevation, and the days when the slope of the linear fit of Tair and Twb (SM) as a function of elevation was positive (negative). For $24 \%$ and $28 \%$ of the days, respectively, there was no statistically significant correlation of Tair and Twb with elevation. In December the proportion of days (40\% and $46 \%$, respectively) when this relationship pertained was greater than during the period from January to March (16-24\% for Tair, and 17-18\% for Twb). Among those days only on $11.1 \%$ and $11.7 \%$ of the days were there inverted elevation lapse rates for Tair and Twb, respectively, with December again having a higher proportion of days (20\% and 24\%, respectively) having inverted lapse rates for Tair and Twb relative to the period from January to March $(<10 \%$ of days having thermal inversions). As noted above, the result for the numbers for SM hours was very different from the cases for Tair and Twb. Thus, for $>50 \%$ of the days there was no statistically significant linear relationship of SM with elevation, but the proportion of those days having inverted lapse rates $(9.4 \%)$ was less than for Tair and Twb. For SM daily hours there was a clear reduction in the inverted lapse rate with time during the ski season, with average values of 22, 8.3, 4.7, and 2.2 days per month per year for December, January, February, and March, respectively.

Figure 4 shows the average hourly lapse rates for Tair and Twb calculated for the entire dataset. This shows clear sub-daily variability, with steeper lapse rates during the hours in the middle of the day (from 11:00 am to 15:00 pm), when lapse rates were similar to the standard ELR ( -5.9 and $-6.6^{\circ} \mathrm{C} / \mathrm{km}$ for Tair and Twb, respectively). Furthermore, the lapse rates tended to moderate in the evening and during the night, followed by a 
steep reduction in the lapse rates from 4:00 am to 8:00 am, when the lowest lapse rates during the day were recorded $\left(-3.6\right.$ and $-3.9^{\circ} \mathrm{C} / \mathrm{km}$ for Tair and Twb, respectively).

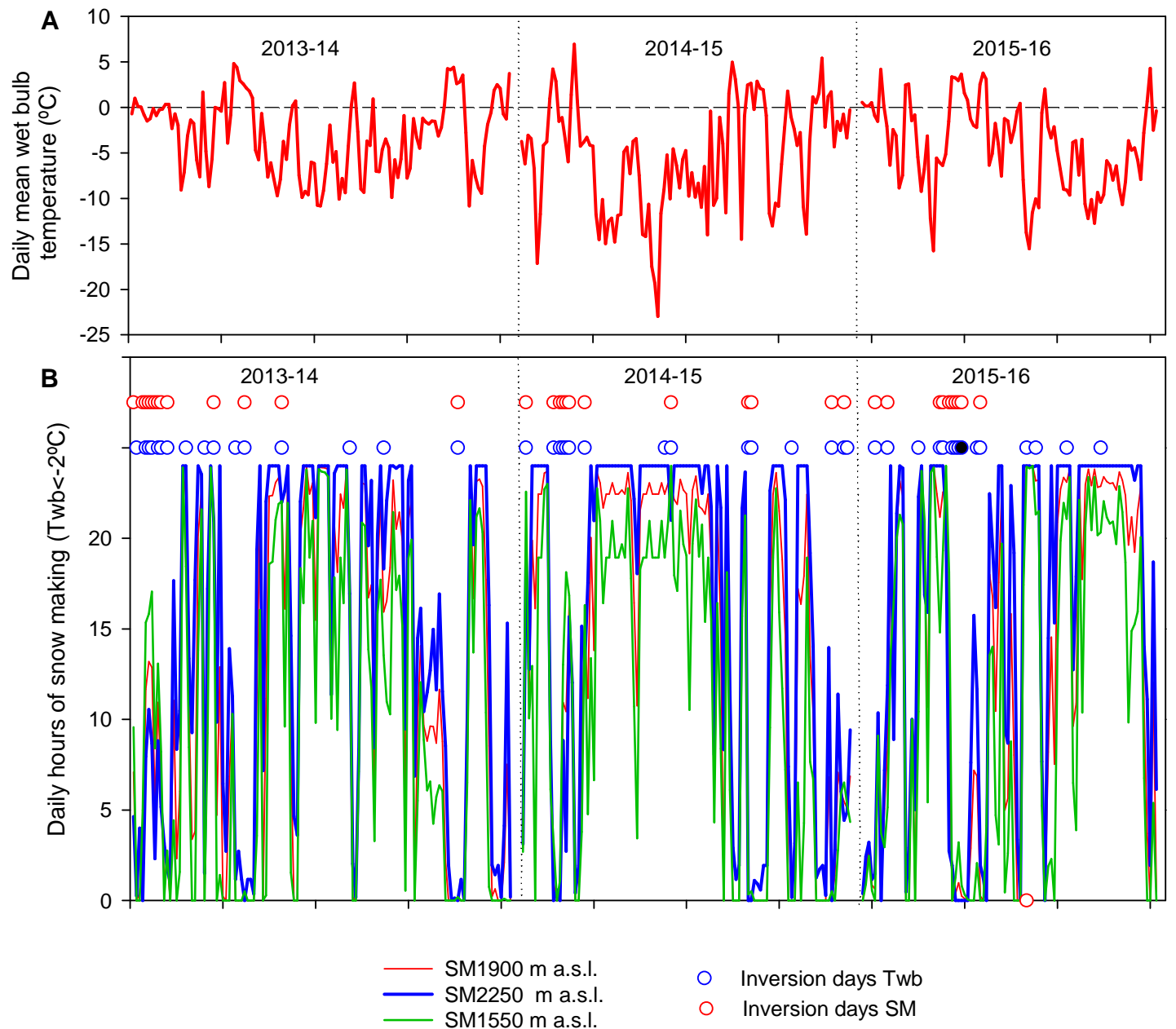

Figure 3. A: Daily mean Twb in the ski resort based on data from the 17 installed sensors. B: Daily number of SM hours (daily hours when Twb $<-2^{\circ} \mathrm{C}$ ) at $1550 \mathrm{~m}$ (green), $1900 \mathrm{~m}$ (red), and $2250 \mathrm{~m}$ (blue), calculated from the linear relationships between SM and elevation. Blue and red circles indicate days having inverted lapse rates for Twb and SM, respectively. 


\begin{tabular}{|c|c|c|c|c|c|c|}
\hline & \multicolumn{3}{|c|}{$\begin{array}{l}\text { \% Days with no significant } \\
\text { correlation with elevation }\end{array}$} & \multicolumn{3}{|c|}{$\begin{array}{l}\text { \% Days with inverted elevation } \\
\text { lapse rate }\end{array}$} \\
\hline & Ta & Twb & SM Days & Ta & Twb & SM Days \\
\hline Dec. & 40 & 46 & 57 & 20 & 24.4 & 22 \\
\hline Jan & 24 & 28 & 53 & 8.6 & 9.6 & 8.3 \\
\hline Feb. & 16 & 17 & 49 & 8.23 & 7.3 & 4.7 \\
\hline Mar. & 17 & 20 & 53 & 7.8 & 5.5 & 2.2 \\
\hline Average & 24 & 28 & 53 & 11.1 & 11.7 & 9.4 \\
\hline
\end{tabular}

Table 1. Total and monthly frequency of days when snowpack does not cools following a statistically significant $(\mathrm{p}<0.05)$ relationship with elevation, and the days when the slope of the linear fit of Tair and Twb (SM) is positive (negative)

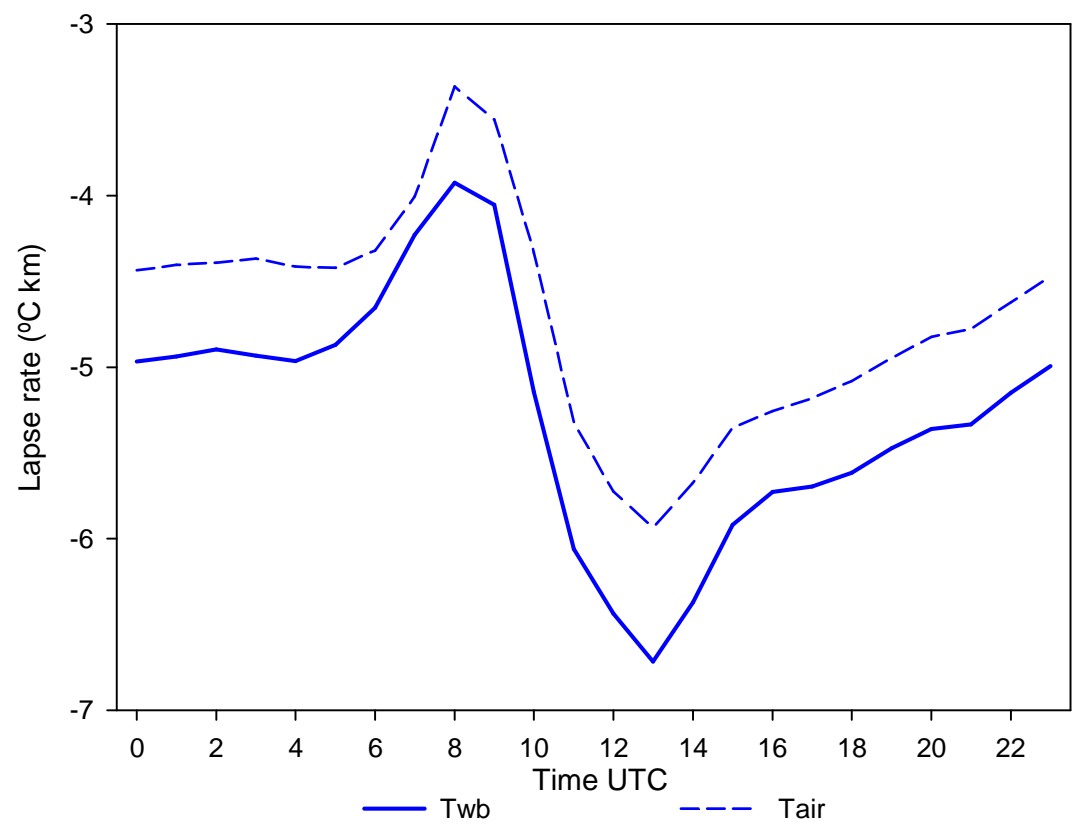

Figure 4. Total average hourly lapse rates for Tair and Twb. The study area is in zone $\mathrm{UTC}+1$.

Figure 5 shows the correlation of Twb and SM lapse rates with daily WS, RH, and Pat. Statistically significant linear correlations were found for WS, RH, and Pat with Twb (p $<0.05)$, and were clearer for RH $(r=-0.57)$ and Pat $(r=0.48)$. Thus, days having lower $\mathrm{RH}$ and higher Pat were associated with the lowest Twb lapse rates, and vice versa. The correlation coefficient for WS $(r=-0.37)$ indicated that the Twb lapse rate decreased with decreasing WS. The Tair and Twb lapse rates were not correlated $(r=0.03)$. The SM lapse rates showed similar relationships with WS, RH, and Pat as those found for Twb, but because of the many days when the SM lapse rate was 0 the correlation 
coefficients were lower, resulting in only the correlation with $\mathrm{RH}$ being statistically significant $(\mathrm{p}<0.05 ; \mathrm{r}=-0.38)$.
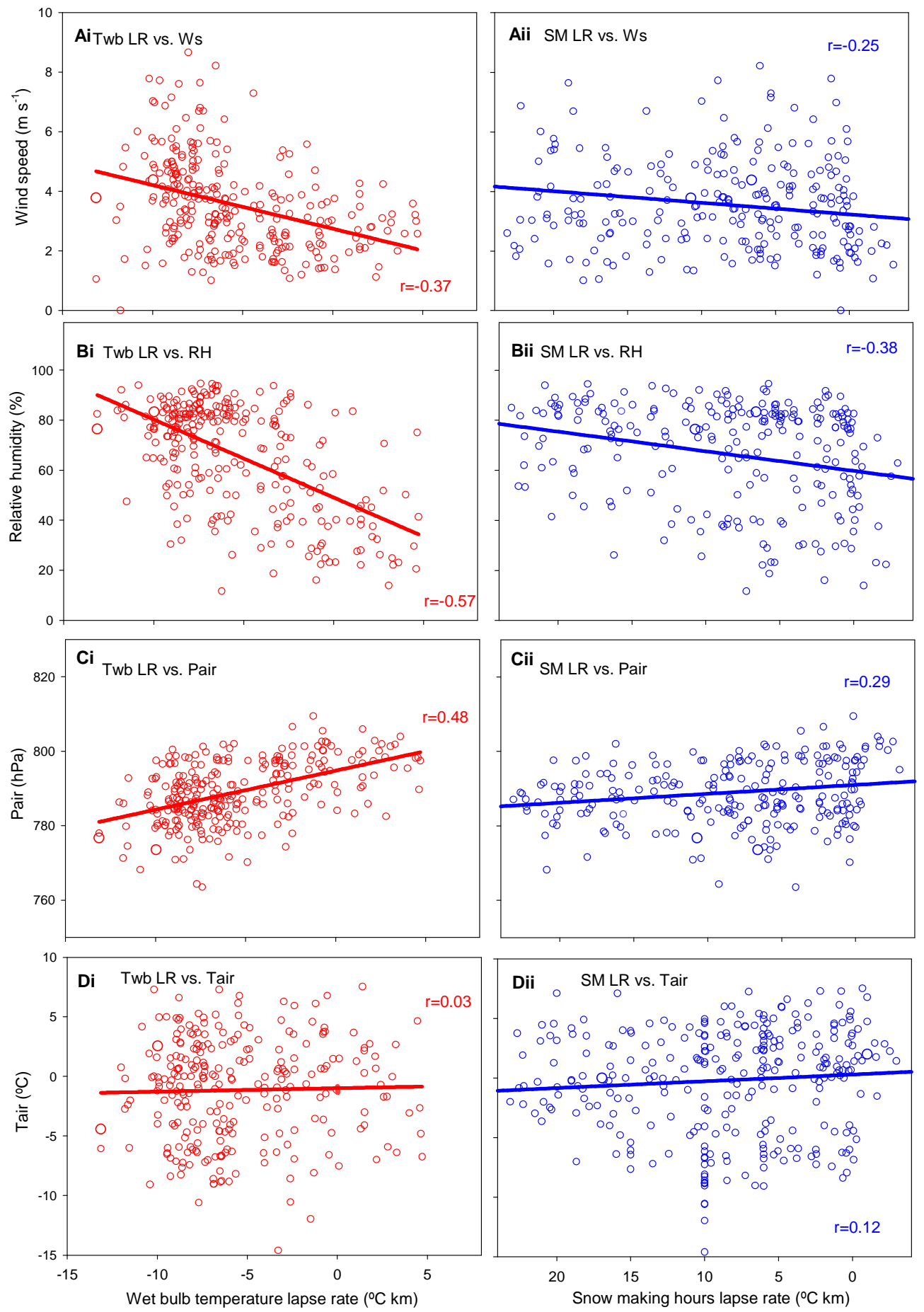

Figure 5. Correlations of wet bulb temperature (Twb; i) and daily snowmaking hours (SM; ii) lapse rates with daily (A) wind speed (Ws), (B) relative humidity (RH), (C) atmospheric pressure (Pair), and (D) air temperature (Tair). 

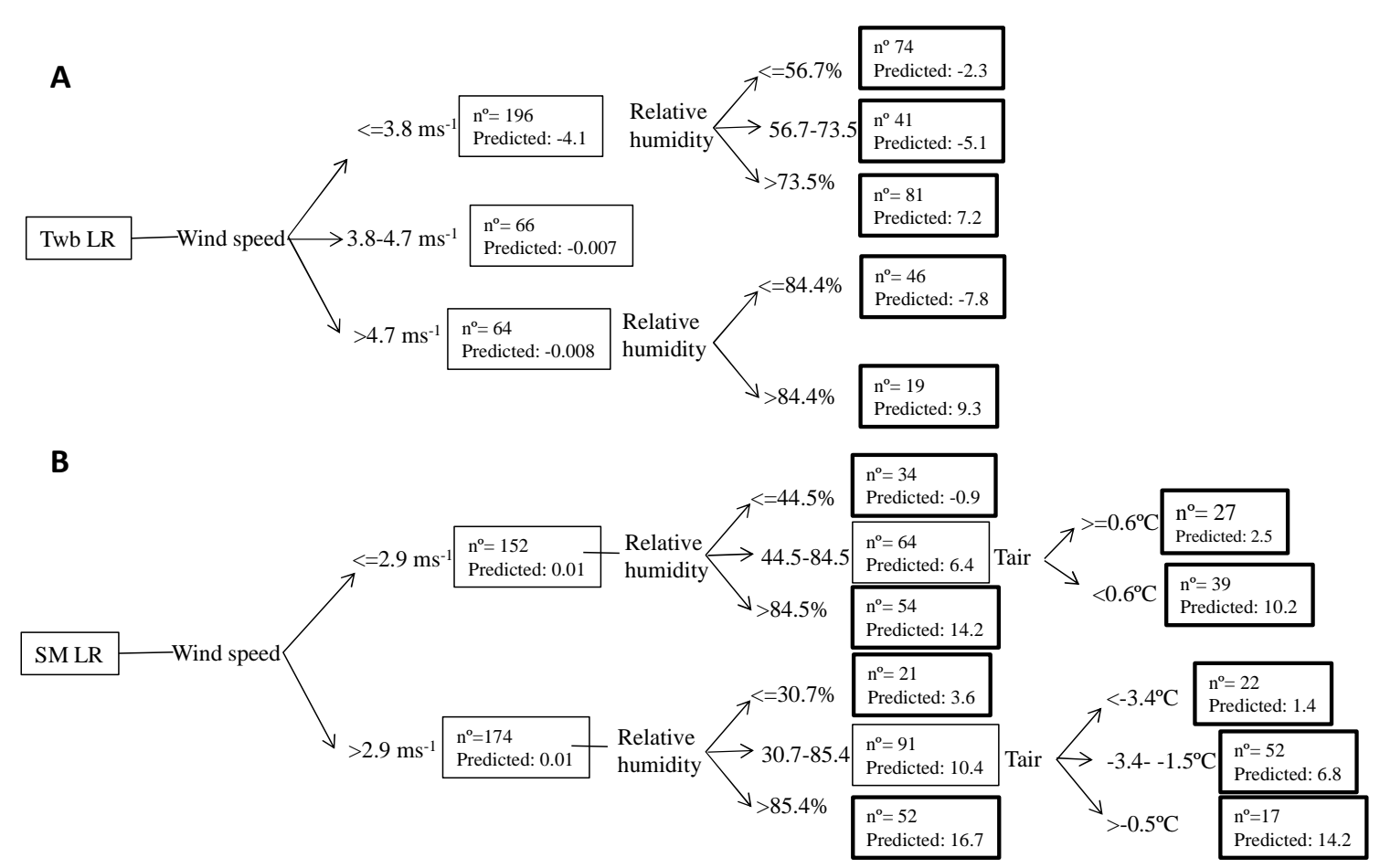

Figure 6. Tree classification models for predicting the Twb and SM lapse rates (Twb LR and SM LR, respectively), based on the variables WS, RH, and Pat. $\mathrm{N}^{\circ}$ is the number of data points at each node. Terminal nodes are framed in a thick line.

Figure 6 show the classification trees for predicting the Twb and SM lapse rates using WS, RH, Tair, and Pat as predictor variables, although Pat was not included in either of the two models. Mean absolute errors (MAEs) of $1.51^{\circ} \mathrm{C} \mathrm{km}^{-1}$ and $0.0021 \mathrm{~h} \mathrm{~km}^{-1}$ were obtained for Twb and SM, respectively. For the Twb lapse rates the first classification was based on three classes of WS $\left(\leq 3.8,3.8-4.7\right.$, and $\left.>4.7 \mathrm{~m} \mathrm{~s}^{-1}\right)$. The days of lowest wind speed were classified into three classes of $\mathrm{RH}$; those having $\mathrm{RH}<56.7 \%$, those having the lowest lapse rate $\left(-2^{\circ} \mathrm{C} \mathrm{km}^{-1}\right)$, and those where the lapse rates increased with increasing RH. Those days in the windiest class (WS $>4.7 \mathrm{~m} \mathrm{~s}^{-1}$ ) and having high RH (> 84\%) were associated with the highest predicted Twb lapse rates (mean value $9^{\circ} \mathrm{C}$ $\left.\mathrm{km}^{-1}\right)$.

The classification tree for SM hours also presents the first split based on WS, but with a lower threshold than for Twb (classifying days having WS values less than and greater than $\left.2.9 \mathrm{~m} \mathrm{~s}^{-1}\right)$. The days having very low WS and low RH $(\leq 44.5 \%)$ values had a low lapse rate $\left(1 \mathrm{~h} \mathrm{~km}^{-1}\right)$, with the slope of the SM lapse rate increasing as $\mathrm{RH}$ increased (up to $14 \mathrm{~h} \mathrm{~km}^{-1}$ for $\left.\mathrm{RH}>85.4 \%\right)$. For days having low WS $\left(<2.9 \mathrm{~m} \mathrm{~s}^{-1}\right)$ and medium RH (44.5-84.5\%), those having Tair $>0.6^{\circ} \mathrm{C}$ had very low lapse rates, so it is unlikely that snow could be made at any elevation. For days having $\mathrm{WS}>2.9 \mathrm{~m} \mathrm{~s}^{-1}$ and $\mathrm{RH}>85.4 \%$, 
the SM lapse rate average was $16 \mathrm{~h} \mathrm{~km}^{-1}$. For days having high WS but low RH $(\leq$ $30.7 \%$ ), the average lapse rate was $3 \mathrm{~h} \mathrm{~km}^{-1}$. Days having intermediate RH (30.7$85.4 \%$ ) were highly dependent on Tair; very low SM lapse rates were found for the coldest days (Tair $<-3.4 ; 1 \mathrm{~h} \mathrm{~km}^{-1}$ ), intermediate SM lapse rates were found when Tair ranged from $-3.4^{\circ} \mathrm{C}$ to $-1.5^{\circ} \mathrm{C}\left(6 \mathrm{~h} \mathrm{~km}^{-1}\right)$, and very high lapse rates were found for days warmer than $-1.5^{\circ} \mathrm{C}\left(14 \mathrm{~h} \mathrm{~km}^{-1}\right)$.
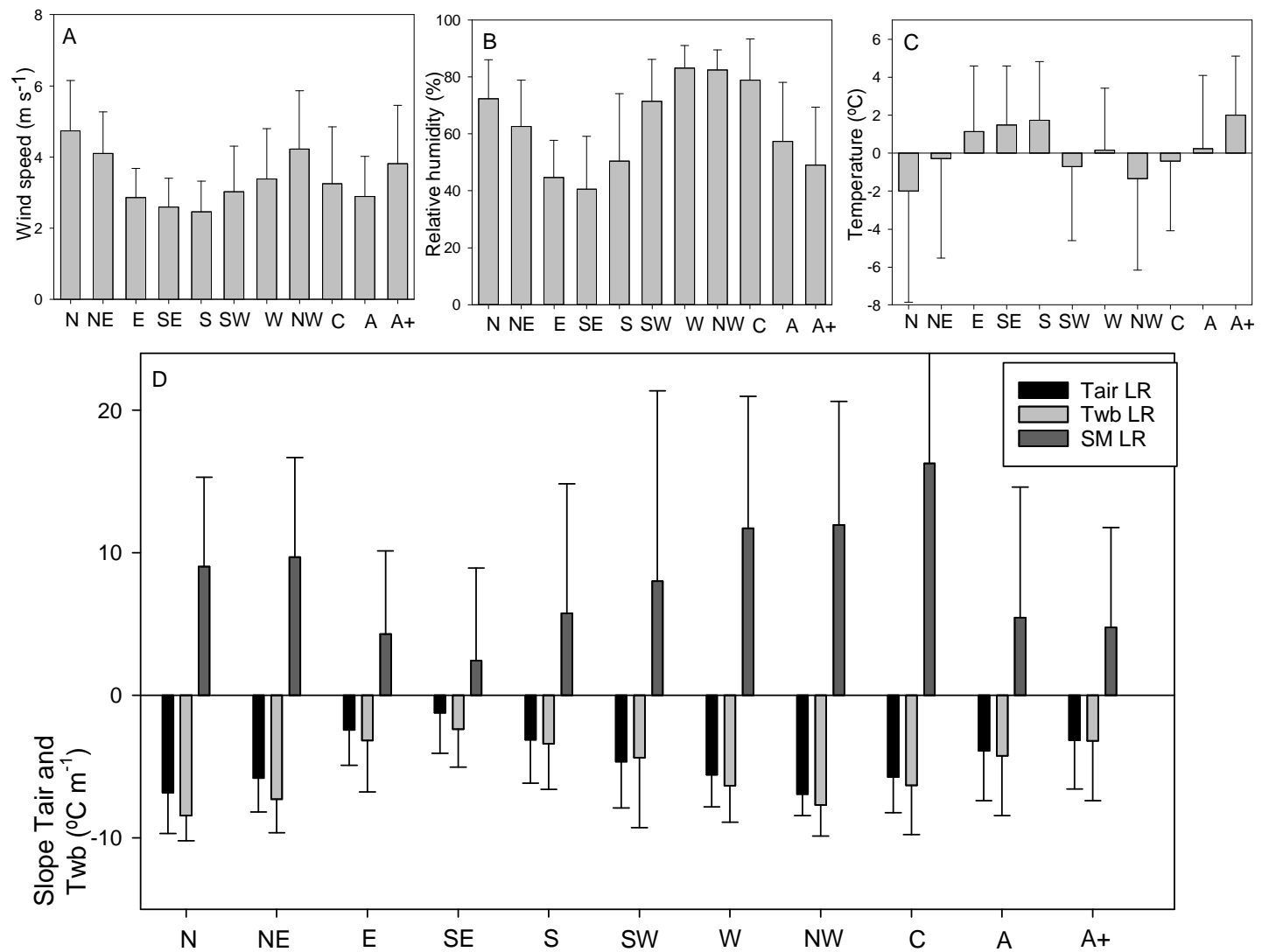

Figure 7. Average (bars) and standard deviation (whiskers) for WS (7A), RH (7B), Tair (7C), and the Tair, Twb, and SM lapse rates (7D) for various weather types over the Iberian Peninsula.

Figure 7A-C shows the averages and standard deviations for the three main explanatory variables (WS, RH, and Tair) identified in the tree models, and the Tair, Twb, and SM lapse rates associated with the various circulation weather types (CWTs) for the Iberian Peninsula during the study period (7D). This shows that the CWTs strongly influenced the lapse rates in the ski area. Thus, the lowest WS (2.5-3 $\left.\mathrm{m} \mathrm{s}^{-1}\right)$ and RH (40-45\%) conditions occurred under the E, SE, and S CWTs. During A weather type conditions the WS was also very low $\left(2.9 \mathrm{~m} \mathrm{~s}^{-1}\right)$, increasing to $3.9 \mathrm{~m} \mathrm{~s}^{-1}$ during $\mathrm{A}+$ conditions; but 
low RH (45\%) was associated with the A+ type, and mean RH of 59\% was associated with the A type. This explains why the days on which SE, E, S, A+, and A CWTs occurred had (in increasing order of importance) the lowest Tair and Twb lapse rates. In addition, these CWTs were also associated with the warmest daily mean Tair values (Fig. 7C), all of which were $>0^{\circ} \mathrm{C}$; this also explains the lowest lapse rates for SM. The SE weather type was associated with the most moderate lapse rates for Tair, Twb, and SM. In contrast, in descending order the highest mean WSs $\left(3.8-4.7 \mathrm{~m} \mathrm{~s}^{-1}\right)$ occurred during $\mathrm{N}, \mathrm{NW}, \mathrm{NE}, \mathrm{W}$, and $\mathrm{C}$ CWTs, while the $\mathrm{W}, \mathrm{NW}, \mathrm{C}, \mathrm{N}$, and $\mathrm{NE}$ types were associated the highest RH conditions (from 81 to $62 \%$, in descending order). The combination of these two variables resulted in the N, NW, and NE CWTs being associated with the steepest Tair and Twb lapse rates (with values very similar to the standard ELR of $-6.5^{\circ} \mathrm{C} \mathrm{km}^{-1}$ ); high but slightly lower lapse rates also occurred during $\mathrm{W}$ and $\mathrm{C}$ conditions. The lowest Tair in the ski area occurred during advections from the $\mathrm{N}$ and NW, but the standard deviations indicated large variability. The Tair values (> or approximately $0^{\circ} \mathrm{C}$ ) during $\mathrm{C}, \mathrm{W}$, and $\mathrm{NE}$ weather types were considerably higher than those associated with N and NW CWTs, resulting in the steepest SM lapse rates occurring during $\mathrm{C}$ days, followed by days under $\mathrm{W}, \mathrm{NW}$, and NE weather types.

Figure 8A shows the percentage of days for each weather type when Tair, Twb, and SM lapse rates exhibited inversions. A $25-40 \%$ of the days under SE, E, and S weather types, and almost $20 \%$ of the days under A and A+ types, there was warming and reduced potential for artificial snow production with increasing elevation. However, as the $\mathrm{A}$ and $\mathrm{A}+$ weather types were much more common than the E, SE, and S types (Fig. 8B), by far the majority of the thermal (Tair and Twb) and SM inversions were associated with $\mathrm{A}$ and $\mathrm{A}+$ weather types. Thus, $35 \%$ and $23 \%$ of the $\mathrm{SM}$ inversions were observed under A and A+ weather types, respectively, whereas the SE, S, SW, E, and $\mathrm{W}$ types were associated with only $16,12,9$, and $5 \%$, respectively, of the total SM inversions during the three ski seasons in the study. 


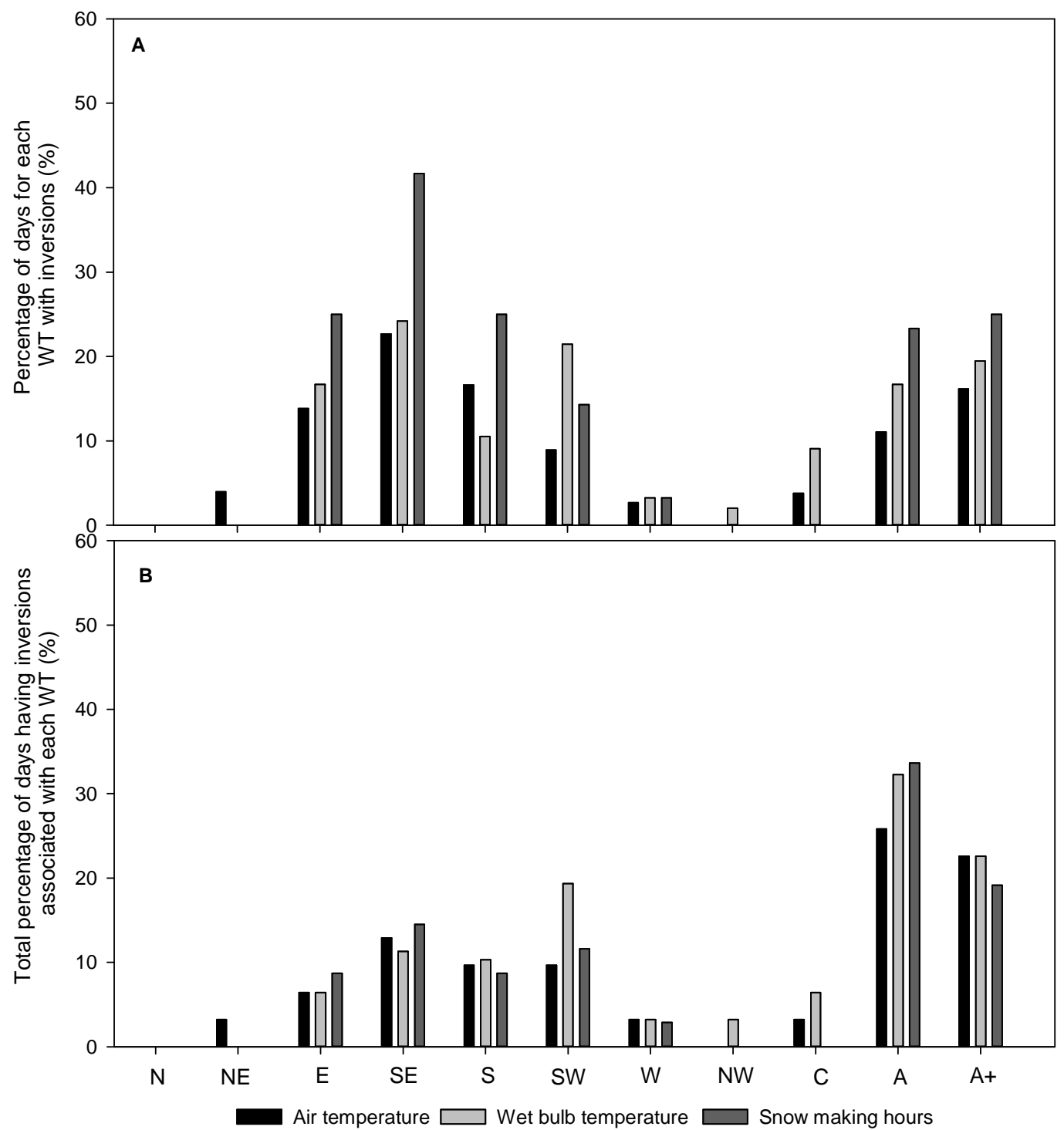

Figure 8. Percentage of days for each weather type with inversions in the Tair, Twb, and SM relationship with elevation (A); and the total percentage of days having inversions associated with each weather type (B).

\section{Discussion}

This study showed that Tair and Twb lapse rates were subject to strong sub-daily and daily variability in the Formigal ski area from December to March during the 2012-13, 2013-14, and 2014-15 ski seasons. The Tair and Twb lapse rates showed almost the same daily fluctuations, and the long-term average for both was well below the average standard environmental lapse rate for dry temperature $\left(-6.5^{\circ} \mathrm{C} \mathrm{km}^{-1}\right)$, with the Twb lapse rate $\left(-5.2^{\circ} \mathrm{C} \mathrm{km}^{-1}\right)$ being slightly steeper than the Tair lapse rate $\left(-4.9^{\circ} \mathrm{C} \mathrm{km}^{-1}\right)$. The Twb lapse rate controlled the elevation dependence of SM, but SM was also 
strongly controlled by Tair because for very cold and very warms days the SM lapse rate was close to 0 independently of the Twb lapse rate. For this reason, the correlation coefficients between elevation and SM were considerably lower than those for Tair and Twb. The average SM lapse rate was $8 \mathrm{~h} \mathrm{~km}^{-1}$, reflecting marked differences in the potential for production of artificial snow within the ski resort. The study also identified that there were a number of days where an inversion in the lapse rate occurred with increasing Tair and Twb (11.1\% and $11.7 \%$ of the studied days, respectively), and a decrease of SM occurred with elevation (9.4\% of the days).

Because this study focused only on the ski season (from December to March) it did not identify clear monthly variability in the Tair and Twb lapse rates, as has been reported in many studies based on the entire year (Roland et al., 2002; Tang and Fang, 2006); these studies have generally shown that the weakest gradients occur in winter (Blanford et al., 2008; Kirchner et al., 2013; Kattel et al., 2015). Nonetheless, December had by far the least steep air temperature lapse rate and the highest number of thermal inversions. The SM lapse rate is closely related to Tair, but showed more marked monthly changes than the Tair and Twb lapse rates, and increased continuously from December to March as Tair progressively increased. The strong SM lapse rates that occurred in March (10.3 $\mathrm{h} \mathrm{km}^{-1}$ ) suggest that at the end of the snow season this measure is useful at high elevations, but of very limited value for lower parts of the ski area, which are the most problematical for skiing because of the shallow snowpack (Gilaberte et al., 2017). We also found considerable diurnal variability in the Tair and Twb lapse rates; this needs to be taken into consideration when estimating SM productivity, as the weakest lapse rates occurred during the midnight to early morning period, when usually more artificial snow is produced.

The marked daily variability of the Tair and Twb lapse rates showed strong negative linear correlations with relative air humidity and wind speed, with the most humid and windiest days exhibiting the steepest rates. Similar relationships have been found for Tair lapse rates in other geographic areas. Thus, Kattel et al. $(2013,2015)$ reported that the difference between wet and dry air conditions was the most important factor controlling the near surface lapse rates in the Himalayas. Pepin et al. (1999) and Li et al. (2013) also reported a negative relationship between lapse rates and relative humidity in northern England and China, respectively. Negative relationships between WS and Tair lapse rates have been reported for the Swiss Alps (Kirchner et al., 2013) and the Pyrenees (Pages and Miro, 2010). Atmospheric pressure (Pat) was also strongly 
positively correlated with the Tair and Twb lapse rates. This variable also exhibited high collinearity with $\mathrm{RH}$ and WS, so seems to be redundant in explaining the temporal dynamics of lapse rates when information on RH and WS is available. However, it may be a useful indicator of temporal fluctuations in lapse rates in regions where limited meteorological information is available, as Pat tends to exhibit a relatively homogeneous behavior over large areas, including in complex topography, and where reliable gridded datasets covering long-term periods are available (Allan, 2006). The temporal dynamics of the SM lapse rates was more complex. Thus, correlations with meteorological variables were lower than Twb because the average Tair in the ski resort led to 0 or 24 SM hours independently of the magnitude of the atmospheric variables.

A regression tree model enabled reliable classification of days into groups (nodes) according to various thresholds of RH and WS that had similar Twb lapse rates. This type of classification may be useful for managers of ski areas in estimating the spatial distribution of SM effectiveness, based on short-term weather forecasts.

Tair was a good predictor of the temporal fluctuation of SM hours lapse rates. The regressions tree models used Tair to identify which days having steep Twb lapse rates led to strong elevational differences in SM hours, and which days had an SM lapse rate of 0 as a consequence of sufficiently cold or warm conditions, ensuring successful SM throughout the ski area.

This study also confirmed that weather types (CWTs) tightly control RH, WS, and Tair at the Formigal ski resort. Thus, major differences in the Tair, Twb, and SM lapse rates occurred in the study area, depending on the CWTs. Knowledge of the characteristics of the air masses associated with different CWTs has previously been identified as useful in understanding the temporal dynamics of air temperature lapse rates (Blanford et al., 2008; Holden and Rose 2011; Kirchner et al., 2013).

We found that the SE weather type was associated with the lowest RH and WS, and high temperature explained the most moderate Tair, Twb, and SM lapse rates. The E, SE, S, A, and A+ weather types shared the same conditions, with obvious shadings, mentioned for SE. The A and A+ types are among the most common weather types over the Iberian Peninsula during the winter months (López-Moreno and Vicente-Serrano, 2007; Navarro-Serrano and López-Moreno, 2017), which explains why winter lapse rates are much less than the standard average ELR $\left(-6.5^{\circ} \mathrm{C} \mathrm{km}^{-1}\right)$, and that the majority of thermal inversions at Formigal (and in the Pyrenees) are because of the occurrence of anticyclonic periods (Pepin and Kidd, 2006), which are particularly persistent in 
December and early January (Pages and Miró, 2010). Cyclonic systems and advections from the N, NW, NE cause the windiest, most humid, and coldest conditions. Thus, the steepest Tair and Twb lapse rates were observed during $\mathrm{N}$ and NW weather types, followed by NE and cyclonic conditions, while the steepest lapse rates for SM occurred during $\mathrm{C}, \mathrm{W}, \mathrm{NE}$, and NW weather types, when Tair was higher than during the $\mathrm{N}$ weather type, or the lapse rates exhibited large variability associated with marked elevational differences in SM production.

As the occurrence of CWTs over a given area is normally controlled by hemisphericscale atmosphere circulation, strong interannual differences occur for the most common CWTs (Buisan et al., 2015). This may be one of the main explanations for the significant differences reported in year to year Tair lapse rates (Holden and Rose, 2011). Thus, the availability of multi-year detailed datasets is necessary to fully understand the dynamics of regional-based lapse rates.

\section{Conclusions}

This study shows that the dynamics of Tair lapse rates must be understood to enable analysis of Twb lapse rates and assessment of spatial differences in the potential for snowmaking within a ski resort. At the Formigal ski resort an increase in elevation of $1000 \mathrm{~m}$ caused average cooling of $4.9^{\circ} \mathrm{C}$ and $5.2^{\circ} \mathrm{C}$ for Tair and Twb, respectively, equating to 8-hours difference in artificial snow production per day. The lapse rates for Tair, Twb, and SM showed strong diurnal, daily, and monthly variability, mostly driven by variability in relative humidity and wind speed (both negatively correlated with lapse rates); these parameters were closely related to the weather types dominating at the synoptic scale. The smoothest lapse rates occurred under advections from the southeast, and to a lesser extent from the east and south and under anticyclonic conditions. The steepest Tair and Twb lapse rates were observed during north and northwest advections, whilst the steepest rates for SM were observed during days involving cyclonic circulation and advections from the northeast. Identification of the relationships of meteorological and synoptic conditions to the magnitude of the lapse rates provides useful information enabling ski area managers to forecast the short-term potential for production of artificial snow. Decadal variability in atmospheric circulation patterns may impact on the magnitude of Tair and Twb. In addition, the lapse rates for snow making are also dependent on air temperature. Thus, the climate warming projected for the majority of mountain areas is likely to have a major effect on the overall capacity to 
produce artificial snow, but will also increase the spatial heterogeneity for potential snowmaking.

\section{Acknowledgements}

This study was funded by the research project CGL2014-52599-P "Estudio del manto de nieve en la montaña española y su respuesta a la variabilidad y cambio climatico" (Ministry of Economy and Development, MINECO). We thank the ski resort of Formigal for its support in this research.

\section{References}

Allan, R., Ansell, T. 2006. A new globally complete monthly gridded mean sea level pressure dataset (HadSLP2): 1850-2004. Journal of Climate 19, 5816-5842.

Blandford, T. R., Humes, K. S., Harshburger, B. J., Moore, B. C., Walden, V. P., Ye, H. 2008. Seasonal and Synoptic Variations in Near-Surface Air Temperature Lapse Rates in a Mountainous Basin. Journal of Applied Meteorology and Climatology 47(1), 249-261.

Breiman, L., Friedman, J.H., Olshen, R.A., Stone, C.J. 1984. Classification and Regression Trees. Chapman and Hall, New York.Brutsaert, W. 1998. Land-surface water vapor and sensible heat flux: Spatial variability, homogeneity, and measurement scales, Water Resour. Res. 34(10), 2433-2442, doi:10.1029/98WR01340.

Buisan, S., Saz, M.A., López-Moreno, J.I. 2015. Spatial and temporal variability of winter snow and precipitation days in the western and central Spanish Pyrenees. International Journal of Climatology 35, 259-274.

Fassnacht, S.R., Heun, C.M., López-Moreno, J.I., Latron, J. 2010. Variability of snow density measurements in the Esera valley, Pyrenees mountains, Spain. Cuadernos de Investigación Geográfica 36(1), 59-72.

Frederick, J.E. 2008. Principles of Atmospheric Science. Ed. Jones and Bartlett. Massachusets, $199 \mathrm{p}$.

Gardner, A.S., Sharp, M. J., Koerner, R. M., Labine, C., Boon, S., Marshall, S. J., Burgess, D. O., Lewis, D., Gardner, A. S., Sharp, M. J., Koerner, R. M., Labine, C., Boon, S., Marshall, S. J., Burgess, D. O. and Lewis, D. 2009. Near-Surface Temperature Lapse Rates over Arctic Glaciers and Their Implications for Temperature Downscaling. Journal of Climate 22(16), 4281-4298. 
Gilaberte, M., Pino, M.R., López, F., López-Moreno, J.I. 2014. Impacts of climate change on ski industry. Environmental Science and Policy 44, 51-66.

Gilaberte, M., López-Moreno, J.I., Morán-Tejeda, E., Jerez, S., Alonso-González, E., López-Martín, F., Pino-Otín, M.R. 2017. Assessment of ski condition reliability in the Spanish and Andorran Pyrenees for the second half of the 20th century. Applied Geography 70, 127-142.

Goodess, C. M., Palutikof, J. P. 1998. Development of daily rainfall scenarios for southeast Spain using a circulation - type approach to downscaling. International Journal of Climatology 10, 1051-1083.

Heynen, M., Miles E., Ragettli, S., Buri, P., Immerzeel, W. Pellicciotti, F. 2016. Air temperature variability in a high-elevation himalayan catchment. Annals of Glaciology 57 (71), 212-222.

Holden, J. Rose, R. 2011. Temperature and surface lapse rate change: a study of the UK's longest upland instrumental record. International Journal of Climatology 31(6), 907-919.

Jenkinson, A. F., Collison, P. 1977. An initial climatology of Wales over the North Sea. In Synoptic Climatology Branch memorandum, 62.

Jones, P. D., Hulme, M. and Briffa, K. R. 1993. A comparison of Lamb circulation types with an objective classification scheme. International Journal of Climatology 13(6), 655-663.

Kattel, D. B., Yao, T., Yang, K., Tian, L., Yang, G. and Joswiak, D. 2013. Temperature lapse rate in complex mountain terrain on the southern slope of the central Himalayas. Theoretical and Applied Climatology 113(3-4) 671-682.

Kirchner, M., Faus-Kessler, T., Jakobi, G., Leuchner, M., Ries, L., Scheel, H.-E. and Suppan, P. 2013. Altitudinal temperature lapse rates in an Alpine valley: trends and the influence of season and weather patterns. International Journal of Climatology 33(3) $539-555$.

Lasanta, T., Laguna, M., Vicente-Serrano, S.M. 2007. Do tourism-based ski resorts contribute to the homogeneous development of the mediterranean mountains? A case study in the Central Spanish Pyrenees. Tourism Management 28, 1326-1339.

Lindberg, K., Andersson, T.D., Dellaert, B.G.C. 2001. Tourism development Assessing social gains and losses. Annals of Tourism Research 28, 1010-1030.LópezMoreno, J.I.,Vicente-Serrano, S.M. 2007. Atmospheric circulation influence on the 
interannual variability of snow pack in the Spanish Pyrenees during the second half of the 20th century. Hydrology Research 38(1), 33-44.

Lopez-Moreno, J.I., Goyette, S., Beniston, M. 2009. Impact of climate change on snowpack in the Pyrenees: Horizontal spatial variability and vertical gradients. Journal of Hydrology 374 (3-4), 384-396.

López-Moreno, J.I., Pomeroy, J., Revuelto, J., Vicente-Serrano, S.M. 2013. Response of snow processes to climate change: spatial variability in a small basin in the Spanish Pyrenees. Hydrological Processes 27 (18), 2637-2650.

López-Moreno, J.I., Gascoin, S., Herrero, J., Sproles, E.A., Pons, M., Hanich, L., Boudhar, A., Musselman, K.N., Molotch, N.P., Sickman, J., Pomeroy, J. 2017. Different sensitivities of snowpack to warming in Mediterranean climate mountain areas. Environmental Research Letters 12, 074006.

Marshall, S. J., Sharp, M. J., Burgess, D. O. and Anslow, F. S. 2007. Near-surfacetemperature lapse rates on the Prince of Wales Icefield, Ellesmere Island, Canada: implications for regional downscaling of temperature. International Journal of Climatology 27(3), 385-398.

Minder, J.R., Mote, P. W., Lundquist, J.D. 2010. Surface temperature lapse rates over complex terrain: Lessons from the Cascade Mountains. Journal of Geophysical Research 115(D14), D14122.

Molotch, N.P., Colee, M.T., Bales, R.C., Dozier, J. 2005. Estimating the spatial distribution of snow water equivalent in an alpine basing using binary regression tree models: the impact of digital elevation data and independent variable selection. Hydrological Processes 19, 1459-1479.

Navarro-Serrano, F.M., López-Moreno, J.I. 2017. Spatio-temporal analysis of snowfall events in the Spanish Pyrenees and their relationship to atmospheric circulation. Cuadernos de Investigación Geográfica/Geographical Research Letters 43(1), 233-254.

Nunez, M., Calhoun, E. A. 1986. A note on air temperature lapse rates on Mount Wellington, Tasmania. Papers and Proceedings of the Royal Society of Tasmania Tasmania. Pap. Proc. R. Soc. Tasm. 12012(120), 11-15.

Pagès, M., Miró, J. R. 2009. Determining temperature lapse rates over mountain slopes using vertically weighted regression: a case study from the Pyrenees. Meteorological Applications 17(1), 53-63. 
Pepin, N. 2001. Lapse rate changes in northern England. Theoretical and Applied Climatology 68(1-2), 1-16.

Pepin, N., Kidd, D. 2006. Spatial temperature variation in the Eastern Pyrenees. Weather 61(11), 300-310.

Pepin N.C., Lundquist, J.D. 2008. Temperature trends at high elevations: Patterns across the globe, Geophys. Res. Lett. 35, L14701.

Pons, M., López-Moreno, J. I., Rosas-Casals, M., Jover, E. 2015. The vulnerability of Pyrenean ski resorts to climate-induced changes in the snowpack. Climatic Change, 131(4). http://dx.doi.org/10.1007/s10584-015-1400-8.

Revuelto, J., López-Moreno, J.I., Azorin-Molina, C., Vicente-Serrano, S.M. 2014. Topographic control on snowpack distribution in a small catchment in the central Pyrenees: intra- and inter-annual persistence. The Cryosphere 8 (5), 1889-2006.

Revuelto, J., Azorin-Molina, C., Alonso-González, E., Sanmiguel-Vallelado, A., Navarro-Serrano, F., Rico, I., and López-Moreno, J. I. 2018: In situ observations of meteorological variables and snowpack distribution at the Izas Experimental Catchment (Spanish Pyrenees): The importance of high quality data in sub-alpine ambients, Earth Syst. Sci. Data, 9, 993-1005, https://doi.org/10.5194.

Rixen, C., Teich, M., Lardelli, C., Gallati, D., Pohl, M., Pütz, M., Bebi, P. 2011. Winter Tourism and Climate Change in the Alps: An Assessment of Resource Consumption, Snow Reliability, and Future Snowmaking Potential Source. Mountain Research and Development 31(3), 229-236.

Roland, C. 2003. Spatial and Seasonal Variations of Air Temperature Lapse Rates in Alpine Regions. Journal of Climate 16(7), 1032-1046.

Scott, D., Hall, C.M., Gössling,S. 2012. Tourism and climate change: Impacts, adaptation and mitigation. London:Routledge.

Spandre, P., François, H., Thibert, E., Morin, S., George-Marcelpoil, E. 2017. Determination of snowmaking efficiency on a ski slope from observations and modelling of snowmaking events and seasonal snow accumulation, The Cryosphere 11, 891-909, https://doi.org/10.5194/tc-11-891-2017.

Steiger, R., Mayer, M. 2008. Snowmaking and Climate Change. Future Options for Snow Production in Tyrolean Ski Resorts. Mountain Research and Development 28, 34, 292-298.

Stull, R. 2011. Wet-Bulb Temperature from Relative Humidity and Air Temperature. Journal of Applied Meteorology and Climatology 50, 2257-2269. 
Tang, Z.Y., Fang, J.Y. 2006. Temperature variation along the northern and southern slopes of Mt. Taibai, China, Agric. For. Meteorol. 139(3-4), 200-207.

Thayyen, R. J., Gergan, J. T., Dobhal, D. P. 2005. Lapse rate of slope air temperature in a Himalayan catchment - a study from Dingad (Dokriani Glacier) basin, Garhwal Himalaya, India, Bull. Glaciol. Res. 22, 19-25.

Trigo, R. M.; Dacamara, C.C. 2000. Circulation Weather Types and their influence on the Precipitation regime in Portugal. International Journal of Climatology 20, 15591581.

Uhlmann, B., Goyette, S. and Beniston, M. 2009. Sensitivity analysis of snow patterns in Swiss ski resorts to shifts in temperature, precipitation and humidity under conditions of climate change. Int. J. Climatol. 29, 1048-1055. 